\title{
Review
}

\section{The Paris System for Reporting Urinary Cytology: The Quest to Develop a Standardized Terminology}

\author{
Güliz A. Barkan ${ }^{a}$ Eva M. Wojcik ${ }^{a}$ Ritu Nayar ${ }^{b}$ Spasenija Savic-Prince ${ }^{c}$ \\ Marcus L. Quek ${ }^{d} \quad$ Daniel F.I. Kurtycz ${ }^{\mathrm{e}}$ Dorothy L. Rosenthal ${ }^{f}$ \\ ${ }^{a}$ Department of Pathology, Loyola University Healthcare System, Maywood, Ill., and ${ }^{b}$ Department of Pathology, \\ Northwestern Memorial Hospital, Chicago, III., USA; 'Institute of Pathology, University Hospital Basel, Basel, \\ Switzerland; d Department of Urology, Loyola University Health Systems, Maywood, Ill., e Department of Pathology \\ and Laboratory Medicine, Wisconsin State Laboratory of Hygiene, University of Wisconsin School of Medicine and \\ Public Health, Madison, Wis., and f Department of Pathology, The Johns Hopkins University, Baltimore, Md., USA
}

\section{Key Words}

The Paris System · Urine · Standardized reporting terminology $\cdot$ Bladder cancer

\begin{abstract}
The main purpose of urine cytology is to detect high-grade urothelial carcinoma (HGUC). With this principle in mind, The Paris System (TPS) Working Group, composed of cytopathologists, surgical pathologists, and urologists, has proposed and published a standardized reporting system that includes specific diagnostic categories and cytomorphologic criteria for the reliable diagnosis of HGUC. This paper outlines the essential elements of TPS and the process that led to the formation and rationale of the reporting system. The Paris System Working Group, organized at the 2013 International Congress of Cytology, conceived a standardized platform on which to base cytologic interpretation of urine samples. The widespread dissemination of this approach to cytologic examination and reporting of urologic samples and the scheme's universal acceptance by pathologists and urologists is critical for its success. For urologists, understanding
\end{abstract}

the diagnostic criteria, their clinical implications, and the limitations of TPS is essential if they are to utilize urine cytology and noninvasive ancillary tests in a thoughtful and practical manner. This is the first international/inclusive attempt at standardizing urinary cytology. The success of TPS will depend on the pathology and urology communities working collectively to improve this seminal paradigm shift, and optimize the impact on patient care.

(c) 2016 S. Karger AG, Basel

\section{Introduction}

More than five decades ago, Dr. George Papanicolaou hypothesized that microscopic evaluation of exfoliated cells in the urine was a potentially useful method to detect

Due to the nature of this paper institutional review board approval is waived. 'The Paris System for Reporting Urinary Cytology: The Quest to Develop a Standardized Terminology' is jointly published by Advances in Anatomic Pathology, Acta Cytologica, and The Journal of the American Society of Cytopathology on behalf of the authors.

\section{KARGER}

E-Mail karger@karger.com www.karger.com/acy
C 2016 S. Karger AG, Base

0001-5547/16/0603-0185\$39.50/0
Correspondence to: Dr. Güliz A. Barkan

Department of Pathology, Loyola University Healthcare System 2160 S. First Ave, Building 110, Room 2238

Maywood, IL 60153 (USA)

E-Mail gbarkan@lumc.edu 
urinary tract malignancies. Since then, urinary tract cytology has been plagued by less than stellar literature that showed problems with sensitivity, accuracy, and reproducibility. Particularly troublesome is the low sensitivity in detecting low-grade noninvasive lesions [1], as well as the lack of standardized diagnostic criteria and wide interobserver variability.

Urine cytology samples constitute a variable, but significant, percentage of daily nongynecologic case volume in any cytopathology practice, and continue to be one of the more difficult specimens that pathologists encounter. Problems include inadequate cellularity of samples, cellular degeneration prior to fixation, as well as unrealistic expectations for diagnosing low-grade urothelial neoplasms (LGUN) by cytology. LGUNs are the most prevalent neoplasms that urologists encounter and are, for the most part, readily visualized via cystoscopy. Additionally, a standardized/comprehensive reporting system for urinary cytology has been missing that is based on the current understanding of the pathogenesis of urothelial carcinoma (UC), and the clinical significance of various types of urinary tract neoplastic lesions. Over 10 years ago, there was an attempt to create such reporting guidelines [2]. The lack of widespread input of the cytopathology community most certainly explains why it has never been generally implemented. In recognition of the need to correct this situation, an international panel of cytopathologists and an urologist with interest in urinary tract cytology convened in Paris in May 2013 at the 18th International Congress of Cytology organized by the International Academy of Cytology. The goal was to discuss ways to improve the reporting and performance of urinary cytology. The value of ancillary tests in the screening and diagnosis of urinary neoplasms was also included for consideration. The original group that met in Paris included cytopathologists (Drs. Dorothy L. Rosenthal, Eva M. Wojcik, Güliz A. Barkan, Lukas Bubendorf, Rana S. Hoda, Ritu Nayar, Stefan E. Pambuccian, Eric Piaton, Momin T. Siddiqui, Margareta Strojan-Fle-zar, and Philippe Vielh) and a urologist (Dr. Marcus L. Quek).

\section{Pathogenetic Bases of The Paris System for Reporting Urinary Cytology}

According to current scientific data, $\mathrm{UC}$ is divided into two major groups, low-grade and high-grade, based on two separate pathogenetic pathways and biologic behavior [3-5].
Approximately $70 \%$ of bladder UCs are non-muscleinvasive (TA/T1), papillary tumors that are usually morphologically categorized as low-grade urothelial carcinoma (LGUC). They have a good prognosis, but may be associated with recurrence and 'progression' to high-grade urothelial carcinoma (HGUC) in approximately $10-15 \%$ of cases. The remaining $30 \%$ are muscle-invasive $(\geq \mathrm{T} 2)$ tumors, which are histologically categorized as highgrade and are associated with worse overall survival than LGUC. The most common molecular alteration in lowgrade noninvasive tumors is an activating mutation of fibroblast growth factor receptor 3 (FGFR3). This mutation is associated with overall favorable disease characteristics [6]. On the other hand, muscle-invasive tumors show a wide range of genomic alterations, with the most commonly seen deletion or mutation of p53 occurring in about $70 \%$ of those tumors. There is a significant body of literature that combines gene expression analysis, whole genome array, comparative genomic hybridization, analysis and mutational analysis of FGFR3, PIK3CA, KRAS, NRAS, TP53, CDKN2A, and TSC1, with resultant identification of 2 separate neoplastic pathways with 2 intrinsic molecular signatures [4]. This genetic evidence has led to the provocative question of whether these are two separate diseases - one, LGUC, associated with an overall good prognosis, and the other, HGUC, associated with a mortality rate of approximately $60 \%$. Therefore, the conclusion of the first meeting of The Paris System Working Group was that the new reporting system would concentrate primarily on the detection of HGUC while minimizing the detection of LGUC, since cytology has a high sensitivity of detecting the former with a poor sensitivity for the latter. This new paradigm became the guiding principle of The Paris System for Reporting Urinary Cytology (TPS).

\section{Standardization of the Reporting System}

Anatomic pathologists serve as consultants to their clinical colleagues and patients, and pathology reports officially document this communication. To help clinicians choose the optimal management options for the patient, reports must accurately and clearly communicate the cytopathologic findings and outcome probability.

Pathologists actively use the terms 'suspicious', 'indeterminate', or 'atypical' - all too often with resultant failure to provide a clear diagnostic and therapeutic path for clinicians. A survey of pathologists and clinicians performed by Redman et al. [7] documented the need for a 
more standardized terminology for reporting cytopathology results (thyroid fine-needle aspirates [FNAs]) and for the education of clinicians on that terminology. Although pathologists have paid attention to all elements of the pathology report (tumor staging summaries, etc. [8]), they have not focused on the issue of report comprehension. In a study looking at surgical pathology reports, surgeons misunderstood pathologists' reports $30 \%$ of the time [9]. One of the issues shared by patients and their advocates on Web sites dedicated to cancer advocacy is that different pathologists and/or different institutions use different highly technical terms to describe the same entities, predictably confusing to both patients and their clinicians.

From a legal perspective, pathologists are advised to issue synoptic reports. Such reporting makes the pathology report clinically relevant, ensures that important diagnostic criteria are considered, standardizes information between institutions, and provides essential therapeutic and prognostic details. Litigation experience stresses that medical malpractice claims can be won or lost based on the quality and content of the medical record [10] and patient management based on the pathologic/cytologic report.

In the United States, widespread implementation of electronic health records is central to federal government goals for improving healthcare quality, safety, and efficiency. The need for a common diagnostic terminology is clearly expressed by the National Committee on Vital and Health Statistics: 'If information in multiple locations is to be searched, shared, and synthesized when needed, we will need ... common vocabularies for personal, clinical and public health information' [11]. The standardization of the pathology reporting language is a key element to fulfill this mandate $[12,13]$.

The Bethesda System (TBS) for Reporting Cervical Cytology terminology, initiated in 1988 [14], led the way for standardized reporting in cytopathology. The goals of TBS terminology were to (1) communicate clinically relevant information from the laboratory to the health care provider; (2) be uniform and reasonably reproducible across different pathologists and laboratories, and with enough flexibility to be adopted in a wide variety of laboratory settings and geographic locations; and (3) reflect the most current understanding of cervical neoplasia. TBS also addressed specimen adequacy, correlated morphology with biology of disease process, 'lumped' biologically equivalent entities, and recognized the reality and poor reproducibility of 'atypia'. TBS has been successful, realizing widespread international implementation leading to the desired standardized terminology and manage-

The Paris System for Reporting Urinary Cytology ment guidelines [15-18], and to funding of research [19]. It has become a model for subsequent development of standardized cytopathology and histopathology reporting consensus efforts $[20,21]$ in other body sites.

In 2009, Crothers et al. [22] described major elements of quality nongynecologic cytology reporting and encouraged the use of standardization. In urinary cytology, despite 2 well-established genetic pathways for the development of bladder cancer, and prognostic implication for LGUC and HGUC, the morphologic terminology for urinary cytology remains disparate and complex.

In order to be adopted and widely accepted by the pathology community, reporting terminology needs to be based on evidence and consensus. It should be applicable to different practice settings; be practical, flexible and concise; and avoid redundancy. With this in mind TPS Working Group convened to form a reporting system that would allow for evolution/change in our understanding of the disease processes, would correlate patient management with optimal clinical outcomes, and would be understood and accepted by the healthcare team taking care of the patient.

\section{The Urologist's Perspective}

Urologists depend on cytology to supplement the routine radiographic and endoscopic evaluation of the urinary tract to ensure that a potentially life-threatening urothelial malignancy is reliably detected. Although it may seem contradictory to see a 'negative' urine cytology report in the face of a well-defined papillary bladder tumor on direct cystoscopic visualization, this simply reflects the fact that the majority of bladder cancers are of low-grade cytomorphology and noninvasive. Most urologists understand the inherent limitations of cytology in diagnosing low-grade and noninvasive lesions due to their cellular cohesiveness and lack of nuclear atypia/dysplasia. These tumors have a low risk of progression. Alternatively, there is little controversy when it comes to the ability of cytology to detect HGUC or carcinoma in situ. These lesions clearly have a potential for recurrence, invasion, metastases, and morbidity/mortality; therefore, patients with high-grade cytomorphology represent the high-risk population most likely to benefit from surveillance evaluation with noninvasive urine cytology.

Given the wide differential diagnosis for hematuria (both gross and microscopic), the cost-effectiveness of voided urine cytology as an initial diagnostic study has been questioned [1]. Most often, hematuria is not a symp- 
tom of neoplasia [23]. Nevertheless, in the appropriate clinical setting, urine cytology may play an important adjunctive role, because the test is relatively cheap and collection methods are either minimally invasive or noninvasive. The initial evaluation for patients at higher risk for bladder cancer (older age, male, smoking history, occupational exposures) and those with unexplained irritative urinary symptoms (potentially due to carcinoma in situ) should include urine cytology. Several groups also advocate the use of cytology in the initial diagnosis and surveillance for HGUC [24-26]. This can be performed at the time of cystoscopy, during which a bladder washing/barbotage may be obtained, thus increasing the cellular yield available for cytologic interpretation. Even for patients who have undergone radical cystectomy with urinary diversion, urine cytology represents an important means to survey the remnant extra-vesical urothelial sites (upper tracts, urethra).

Although cystoscopy is considered the 'gold standard' diagnostic technique for detection of bladder cancer, it is by no means perfect. Diagnostic accuracy depends on the experience of the urologist and the cytopathologist, as well as the clinical suspicion. Knowledge of the results of a urinary marker has been shown to influence how subtle urothelial abnormalities may be viewed [27]. The decision to perform a biopsy of an equivocal lesion is justified if the cytologic diagnosis is Suspicious for HGUC (SHGUC) or HGUC. A negative urine cytology coupled with a normal cystoscopy is quite specific and reassuring that a potentially lethal high-grade malignancy is most likely absent [28]. A diagnosis of a 'positive' or 'suspicious' urine cytology should be thoroughly investigated and followed closely, regardless of the cystoscopic findings [29]. The conundrum rests with the 'atypical' diagnostic category. Some have advocated the use of adjunctive techniques, such as fluorescence in situ hybridization (FISH) testing, to further characterize this cohort and move interpretation into either a non-neoplastic or neoplastic category. Most critical is an understanding by the clinician of what the cytopathologist considers 'atypical' and how that relates to the suspicion for and probability of an underlying malignancy. The smaller the laboratory's frequency of 'atypical' interpretations, the more meaningful that category is to the clinician. Clearly, there are limitations to urine cytology. Microscopic morphology is not a perfect reflection of biologic behavior. This may be due to disease-related factors (poor sensitivity for low-grade noninvasive tumors), the method of sampling (voided versus instrumented), and the experience of the cytopathologist. Urologists should understand these lim-
Table 1. Diagnostic categories for The Paris System for Reporting Urinary Cytology

1 Nondiagnostic/unsatisfactory

2 Negative for high-grade urothelial carcinoma (NHGUC)

3 Atypical urothelial cells (AUC)

4 Suspicious for high-grade urothelial carcinoma (SHGUC)

5 High-grade urothelial carcinoma (HGUC)

6 Low-grade urothelial neoplasm (LGUN)

7 Other: primary and secondary malignancies and

miscellaneous lesions

itations when interpreting the reports. In order to improve the clinical utility of urine cytology, it is important for both urologists and cytopathologists to communicate effectively with each other. The clinical history (symptoms, prior treatments) and cystoscopic findings should be readily available to the cytopathologist in order to optimize the usefulness of the cytology report.

\section{Diagnostic Categories and Morphologic Criteria of The Paris System}

A universally accepted and utilized system for reporting urinary tract cytopathology does not exist. This was eloquently demonstrated and documented by Glatz et al. [30] via an international telecytology quiz on urinary cytology, where the participants failed to agree even on the proposed categories. The goal of TPS is not only to define morphologic criteria for the various categories in urinary tract cytopathology, but also to standardize the reporting system in order to be universally acceptable and globally utilized. The published diagnostic categories are shown in table 1 , and figure 1 shows the algorithmic approach to TPS.

\section{Adequacy}

Unlike surgical pathology, adequacy of the cytopathology specimen is an integral part of the report. For some specimen types, adequacy has been clearly defined (i.e., for cervicovaginal cytology [31, 32] and FNA specimens of the thyroid [33-35]); in others, adequacy criteria have been proposed (pancreaticobiliary system cytology [36], EBUS/EUS-guided FNAs of mediastinal and hilar lymph nodes [37-39]) but are not yet defined or tested; in most other specimen types there are no well-defined, universally accepted adequacy criteria. Adequacy, in general, ensures that the specimen is representative of what is 


\section{Approach to Diagnosis in Urinary Tract}

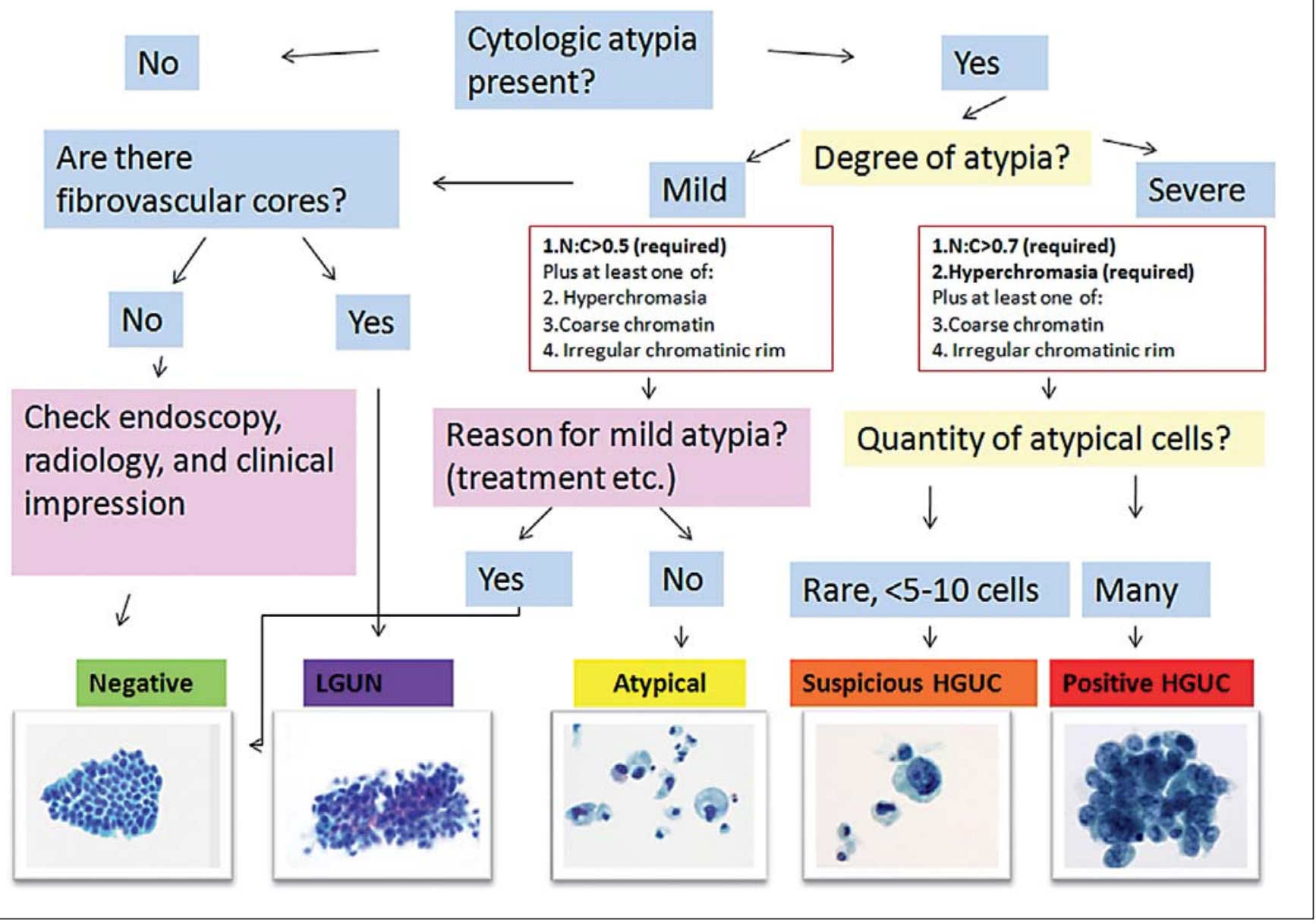

Fig. 1. Algorithmic approach to diagnosis of urinary cytology in The Paris System.

sampled. It is defined according to the type of specimen, which may be truly exfoliated specimens (cerebrospinal fluid, voided urine, serosal cavity fluids) or forced exfoliative cellular samples (Papanicolaou test, bladder washing, or FNA specimens). If the sample contains abnormal cells, no matter how few, the specimen is considered 'adequate for diagnosis'. Otherwise, the definition of adequacy is based on the quantification or at least a semiquantification of the number of cells and/or the volume of voided urine. The adequacy of instrumented urinary tract specimens was recently addressed by an evidencebased study that prospectively and retrospectively evaluated the cellularity of bladder washing specimens. The results supported the conclusion that 2,600 cells or 2 well-visualized urothelial cells per high-power field in 10 consecutive high-power fields may serve as an objective measure of adequacy in instrumented urine specimens processed using the ThinPrep method [40]. Table 2 proposes guidelines for estimating cellularity in instrumented urinary tract specimens. Another study evaluated the volume of voided urine, concluding that specimens larger than $30 \mathrm{ml}$ are more likely to be cellular/satisfactory $[41,42]$.

Regardless of the specimen type (voided urine or instrumented), if the urothelial cells are completely obscured by lubricant or inflammatory cells, this represents an 'unsatisfactory' specimen. Conversely, if there are any atypical cells regardless of the overall cellularity this represents a satisfactory specimen. 
Table 2. Guidelines for estimating cellularity in instrumented urinary specimens

\begin{tabular}{|c|c|c|c|c|c|c|c|c|c|}
\hline $\begin{array}{l}\text { Prep } \\
\text { diameter, } \\
\mathrm{mm}\end{array}$ & $\begin{array}{l}\text { Area, } \\
\mathrm{mm}^{2}\end{array}$ & \multicolumn{2}{|c|}{ FN20 eyepiece $10 \times$ objective } & \multicolumn{2}{|c|}{ FN20 eyepiece $10 \times$ objective } & \multicolumn{2}{|c|}{ FN20 eyepiece $10 \times$ objective } & \multicolumn{2}{|c|}{ FN20 eyepiece $10 \times$ objective } \\
\hline 13 & 132.7 & 42.3 & 62.5 & 676 & 3.9 & 34.9 & 75.8 & 559 & 4.7 \\
\hline 20 & 314.2 & 100 & 26.4 & 1,600 & 1.7 & 82.6 & 32 & 1,322 & 2 \\
\hline
\end{tabular}

Adapted from Solomon and Nayar [32] (page 8).

A
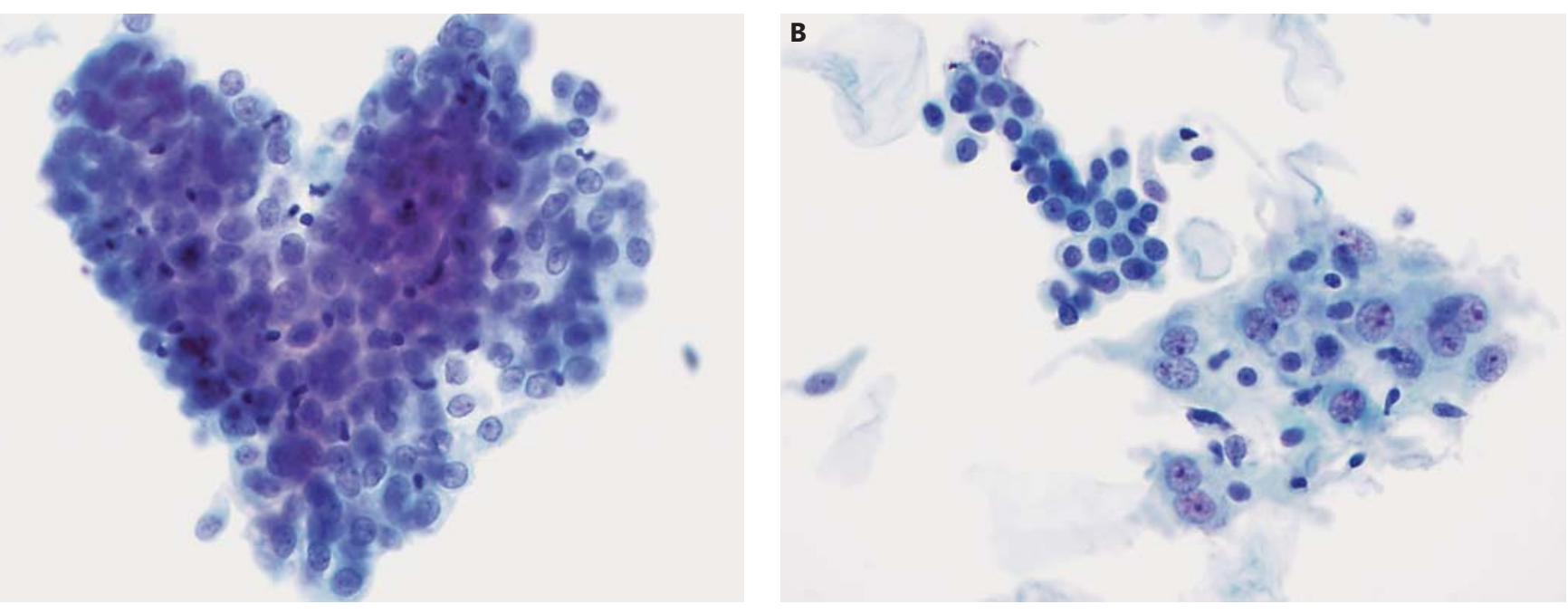

Fig. 2. Negative for high-grade urothelial carcinoma (bladder washing, ThinPrep, Papanicolaou stain, 600×). A A cluster of benign intermediate and basal type urothelial cells with scant cytoplasm, and normochromatic nuclei. B A group of reactive superficial urothelial cells with open chromatin and prominent chromocenters juxtaposed to benign basal type small umbrella cells with scant cytoplasm. The nuclear contours of all these benign cells are relatively smooth and regular.

\section{Negative for High-Grade Urothelial Carcinoma}

The majority of urinary tract specimens fall in this category, negative for high-grade urothelial carcinoma (NHGUC). The most common cellular element is benign superficial urothelial cells, followed by intermediate and basal urothelial cells that are more commonly observed in instrumented specimens. Superficial squamous cells from the female genital tract often outnumber urothelial cells. Benign glandular cells (from cystitis glandularis), squamous cells originating in squamous metaplasia of urothelium or external genital tract skin, and, rarely, benign seminal vesical cells also fall into this category. Groups or fragments of urothelial cells that may be seen in both instrumented and non-instrumented urine specimens should be classified as negative unless the cytomorphology of the cells forming the group fits the criteria outlined under the atypia category. Similarly, changes associated with urolithiasis, treatment-related changes, and polyomavirus (BK virus) cytopathic changes should all be classified as NHGUC [43].

Figure 2A, B depicts benign urothelial cells classified under the NHGUC category.

\section{Atypical Urothelial Cells}

A major goal of TPS was to clarify the ill-defined category of 'atypia' (atypical urothelial cells [AUC]) as much as possible, and minimize the reporting rate of this category. To date, pathologists have not agreed 
Table 3. Comparison of morphologic criteria of abnormal cells in The Paris System for Reporting Urinary Cytology

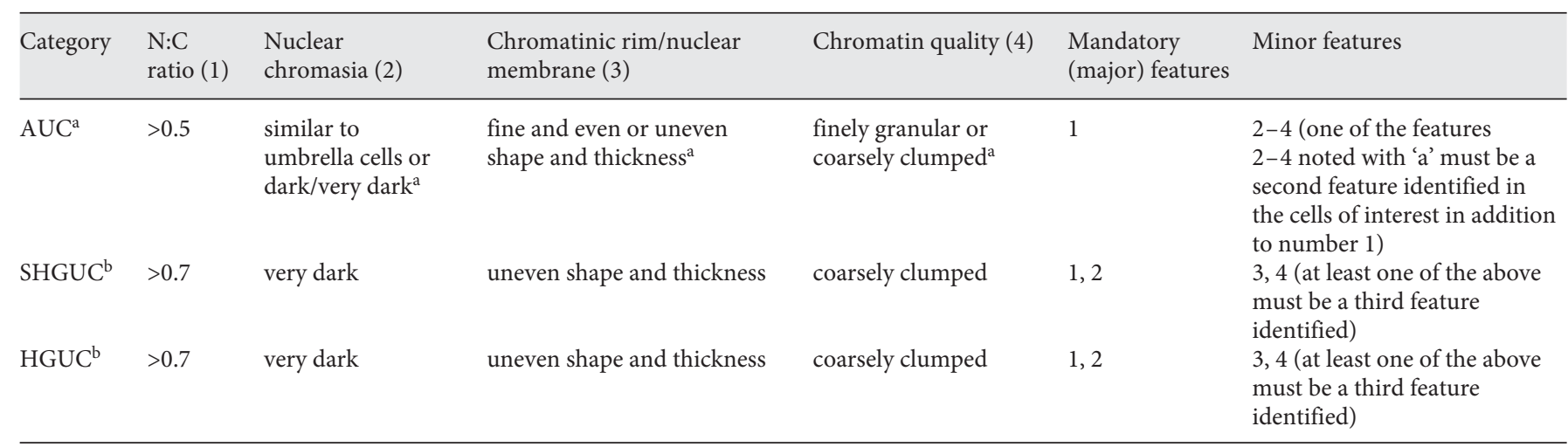

${ }^{a}$ Only one minor feature required. ${ }^{b}$ Only difference is the quantity: SHGUC = very few cells, $5-10$ cells.

upon the general definition of atypia in urinary tract specimens. Some have defined atypia as 'cells that are reminiscent of, but not diagnostic of, HGUC'. Others define it as 'clusters of urothelial cells, suspicious for LGUC', and yet others believe degenerated urothelial cells should be reported as atypical. As a result, there is wide interobserver and intraobserver variability, which is the reason why the rates of atypia vary from 1.9 to $23.2 \%$ among institutions $[44,45]$. In a small survey sent to a voluntary group of US laboratories, the reported percentages of their atypia categories range from 0.8 to $22 \%$ (mean: $12.9 \%$ ). A similar survey sent to 20 international groups including France, Canada, and Japan showed similar results of atypia ranging from 1.8 to 23.7\% (mean: $13.75 \%$ ).

A review of the literature [46-48] and surveys sent out to TPS groups responsible for the AUC and SHGUC chapters concurred on the 4 cytomorphologic features in predicting HGUC: nuclear cytoplasmic ratio, hyperchromasia, irregular nuclear membrane, and coarse chromatin. The criteria for the categories were set using these cytomorphologic features (see fig. 1, table 3).

Therefore, the criteria for diagnosing atypical urothelial cells include one major and one minor criterion. The major or required criterion is the presence of nonsuperficial and nondegenerated urothelial cells with an increased nuclear cytoplasmic $(\mathrm{N} / \mathrm{C})$ ratio $(>0.5)$. The minor criteria, of which only one is required, include: (1) mild nuclear hyperchromasia, (2) irregular nuclear membranes (chromatinic rim or nuclear contour), and (3) irregular, coarse, clumped chromatin. Figure 3 depicts a bladder washing specimen with cytologic atypia, hence classified under AUC.

The Paris System for Reporting Urinary Cytology
In The Bethesda System for Reporting Gynecologic Cytology, the category 'atypical squamous cells' typically raises the possibility of a low-grade intraepithelial lesion and 'atypical squamous cells, a high-grade lesion cannot be excluded' typically raises the possibility of a high-grade squamous intraepithelial lesion. In TPS in both equivocal categories, AUC and SHGUC, the atypia refers to the probability of HGUC. Of course, the prediction of HGUC is much lower in AUC compared with SHGUC.

Usually, management of an AUC diagnosis will have routine follow-up akin to the 'negative' category. By minimizing the atypia rate we will help guide our urology colleagues towards an appropriate management strategy, and reduce patient anxiety related to an indeterminate diagnosis. According to the open ASC Web-based forum on TPS, $97 \%$ of the participants agree that there should be a diagnostic category of AUC, and similarly, $93 \%$ of the participants agree that this category should be kept at the lowest possible rate in order to maintain clinical significance.

\section{Suspicious for High-Grade Urothelial Carcinoma}

This category includes cases with severe urothelial atypia, but falls quantitatively short of a definitive HGUC diagnosis-although the atypia present is beyond the atypia defined in the AUC category. Naturally, the follow-up of cases diagnosed as SHGUC will reveal a higher rate of HGUC compared with that of AUC.

The major or required criteria are the presence of nonsuperficial and nondegenerated urothelial cells with an increased N/C ratio ( $>0.7)$ and severe nuclear hyperchromasia. The minor criteria, of which only one is required, 


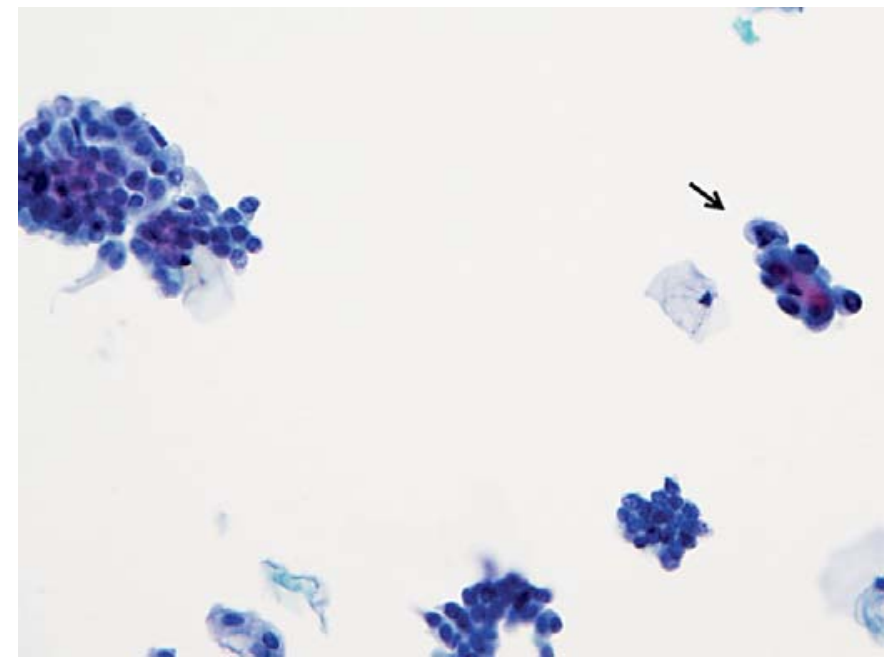

Fig. 3. Atypical urothelial cells (bladder washing, ThinPrep, Papanicolaou stain, $600 \times)$. This urine specimen has very rare cells with slightly higher $\mathrm{N} / \mathrm{C}$ ratio $(>0.5)$, in addition to hyperchromasia. In this atypical cell cluster (arrow) cells are enlarged compared with the neighboring clusters of benign urothelial cells. Degenerative changes make it difficult to further characterize the chromatin pattern. However, the cytomorphologic changes are sufficient to classify this case under 'AUC'.

include: (1) irregular nuclear membranes (chromatinic rim or nuclear contour), and (2) very dark, irregular, coarse, clumped chromatin. Figure 4 depicts a urine specimen with significant cytologic atypia in a few cells, hence classified under SHGUC.

\section{High-Grade Urothelial Carcinoma}

Although urine cytomorphology reporting has evolved over time from the days of George Papanicolaou and Leopold Koss, perhaps the one concept that has remained unchanged is the cytomorphologic characteristics of HGUC. HGUC has been well recognized in urinary tract cytopathology as having the following features: high N/C ratio, nuclear pleomorphism, nuclear membrane irregularity, and severe hyperchromasia $[49,50]$. In addition, coarse chromatin patterns are well described and illustrated. Other features, such as nuclear and cytoplasmic pleomorphism, eccentrically located nuclei, dense cytoplasm, presence of mitotic figures, and apoptotic bodies are also seen in these cases. Prominent nucleoli, isolated malignant cells with enlarged nuclear size, and extensive necrosis have been described as features of HGUC in urine cytology specimens, with necrosis increasing the possibility for invasive disease [51]. According to TPS, the

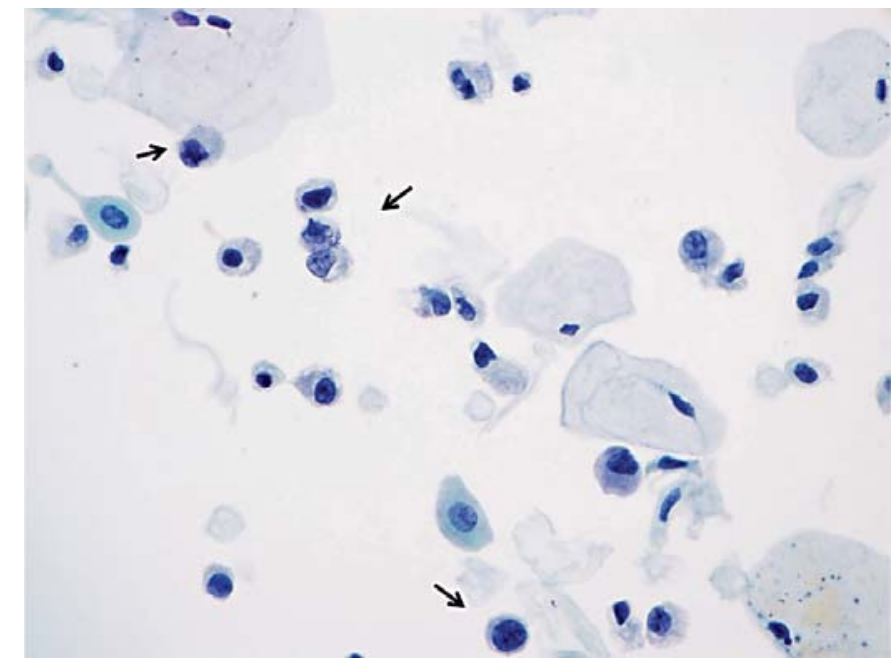

Fig. 4. Suspicious for high-grade urothelial carcinoma (bladder washing, ThinPrep, Papanicolaou stain, 600×). This urine specimen contains rare cells with high N/C ratio ( $>0.7)$, irregular nuclear contours, and coarse chromatin. Compared with the benign urothelial cells, the abnormal urothelial cells are hyperchromatic and are all features of HGUC; however, the paucity of abnormal urothelial cells (arrows) precludes a definitive diagnosis of HGUC. On follow-up this patient had invasive HGUC in the urinary bladder.

necessary morphological features to diagnose HGUC include: a minimum of 5 to 10 severely abnormal urothelial cells with an N/C ratio of 0.7 or greater, with cells showing moderate to severe hyperchromasia, coarse chromatin, and markedly irregular nuclear membrane. Figure 5 depicts a classic HGUC.

\section{Low-Grade Urothelial Neoplasm}

The main goal of TPS is to detect a HGUC, but lowgrade urothelial lesions cannot be discounted. Previous studies list a number of morphologic features that enabled the diagnosis of LGUC, such as minimal nuclear enlargement, nuclear membrane irregularity, density of cytoplasm, and elongated nuclei [52-55]. TPS, however, acknowledges that in the majority of cases a reliable diagnosis of low-grade carcinoma cannot be made, even with the morphologic features listed above. In a recent study by McCroskey et al. [56], most of the features described previously as diagnostic for LGUC were observed almost equally in cases negative for LGUC, regardless of whether the specimens were from the upper or lower urinary tract. Presence of fibrovascular cores, a feature extremely rare in urine specimens, is the only instance when the diagnosis of low-grade papillary lesion in instrumented urine 


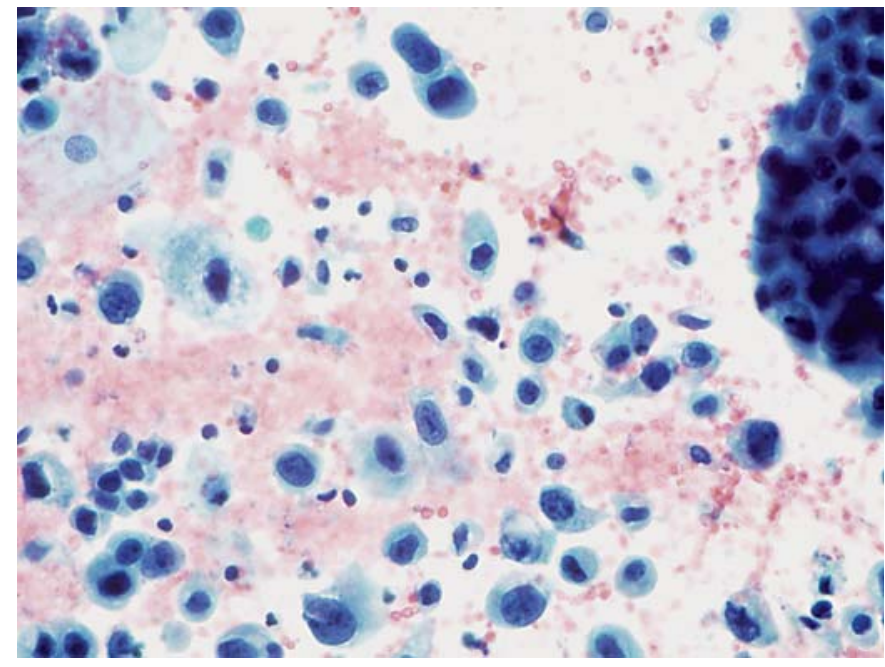

Fig. 5. High-grade urothelial carcinoma (bladder washing, cytospin, Papanicolaou stain, $600 \times$ ). This urine specimen has numerous cells with high $\mathrm{N} / \mathrm{C}$ ratio ( $>0.7)$, demonstrating nuclear hyperchromasia, coarse chromatin, and irregular nuclear membranes. Most cells have a plasmacytoid appearance with eccentrically placed nuclei. The background has a significant number of red blood cells, which is commonly seen in cytospin preparations.

can be made with confidence. Fibrovascular cores can be seen in any low-grade papillary lesion, including papillomas, papillary urothelial neoplasia of low malignant potential, and LGUC. Therefore, for reporting purposes, 'low-grade urothelial neoplasm (LGUN)' is recommended as a diagnostic category. This category is to be used sparingly, and in conjunction with the NHGUC category in order to clarify the conspicuous absence of HGUC. Figure 6 demonstrates LGUN, where the surgical followup was noninvasive LGUC. In TPS, LGUN also serves as a placeholder, awaiting further understanding of the molecular biology of the lesion.

\section{Other Malignancies: Primary, Metastatic and}

Miscellaneous Lesions

Primary malignancies of the urinary bladder, other than of urothelial origin, are rare and typically represent fewer than $5 \%$ of bladder tumors. They include squamous cell carcinoma, adenocarcinoma, and small-cell carcinoma. Their cytologic features are the same as those in other parts of the body.

Secondary malignancies in the bladder occur in fewer than $10 \%$ of bladder tumors. Most of these are direct invasion from prostate, cervix, uterus, or gastro-

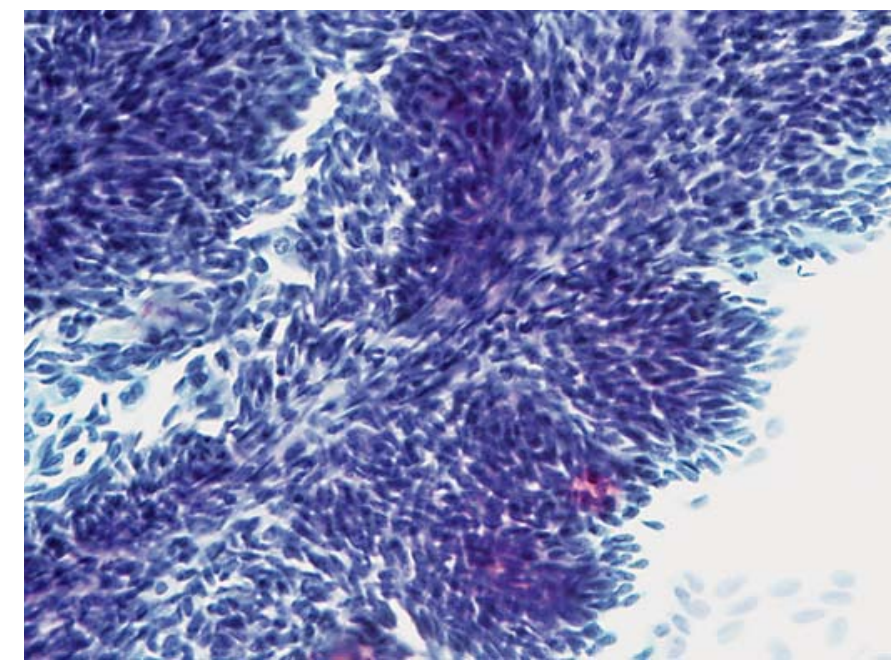

Fig. 6. Low-grade urothelial neoplasm (renal pelvis brushing, conventional preparation, Papanicolaou stain, $400 \times$ ). This is a very cellular urine specimen composed of monomorphic cells. The most striking morphological features are the presence of fibrovascular cores lined by the monomorphic urothelial cells. This is the only sine qua non-morphologic feature to render a diagnosis of LGUN. On follow-up this patient did have a subcentimeter lowgrade papillary urothelial carcinoma.

intestinal tract. The most common distant metastases are malignant melanoma, and carcinomas of stomach, breast, kidney, and lung. Figure 7 is an example of adenocarcinoma of the prostate involving the urinary bladder.

\section{The Use of Ancillary Diagnostic Testing in Urine Cytology}

As mentioned earlier, the diagnosis of 'atypical urothelial cells' is inconclusive for malignancy, and creates a dilemma for the urologist, especially in patients with negative or equivocal findings on ureterocystoscopy. There have been many ancillary studies used for urine cytology, but only a few are currently US Food and Drug Administration (FDA)-approved to be used in the laboratory setting; namely: UroVysion FISH (Abbott Molecular Inc, Des Plaines, Ill., USA), ImmunoCyt (Scimedx, Denville, N.J., USA), BTA stat (Polymedco, Cortlandt Manor, N.Y., USA), and NMP 22 (Allere, Waltham, Mass., USA). The FDA approval for these tests are for voided urine specimens only. 


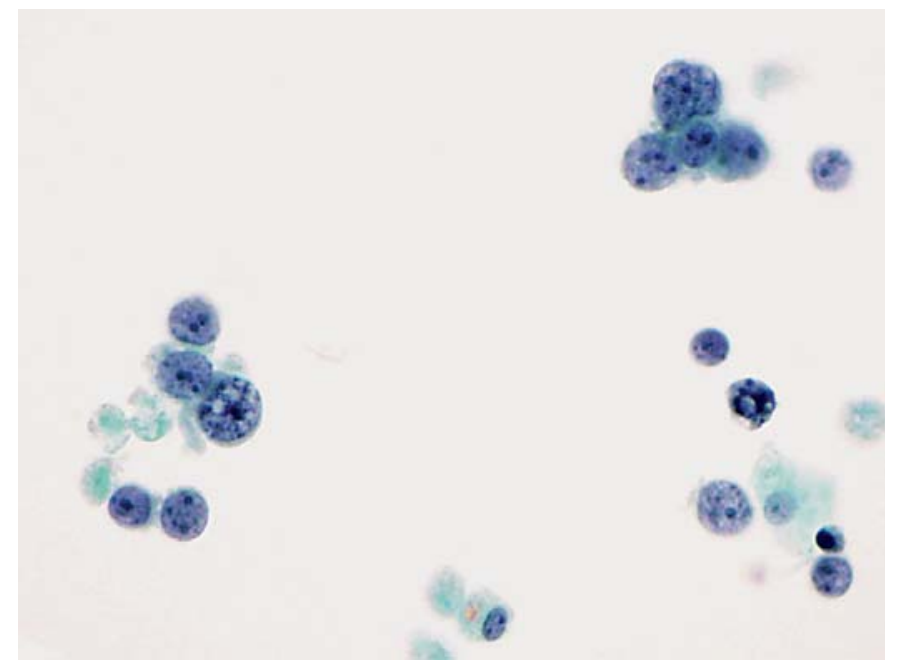

Fig. 7. Prostatic adenocarcinoma involving urinary bladder (bladder washing, ThinPrep, Papanicolaou stain, 600×). This urine specimen demonstrated mostly clusters of cells with high N/C ratio and prominent nucleoli. Although HGUC can show clustering and prominent nucleoli, these features are more commonly observed in adenocarcinomas, especially of prostatic origin. This patient did have a history of prostatic adenocarcinoma, Gleason score $4+4=8$, and the cell block sections showed PSA-positive tumor cells.

Of these, one of the most commonly used to clarify inconclusive cytological findings is the UroVysion FISH test, likely because of its morphologic applicability to the cytopathology laboratory. This multiprobe FISH test was initially developed to improve the detection of invasive HGUC in voided urine and is now FDA-approved for initial diagnosis and surveillance of patients with hematuria [57]. The reported sensitivity and specificity of the test for detection of HGUC vary widely in the literature and have been reported from 8 to $100 \%$ and 29 to $100 \%$, respectively [58]. This variability in the reported performance of the test may be due to lack of standardization of the technical testing procedure and test evaluation. These vulnerabilities include the definition for UroVysion FISH-positivity, prevalence of disease in the population tested, the specimen type (voided urine versus instrumented specimens) and the cellularity of the urinary specimen used for FISH testing.

A cytologic diagnosis of 'positive for malignancy' has a high specificity and positive predictive value of greater than $90 \%$ for the diagnosis of HGUC. In this scenar-

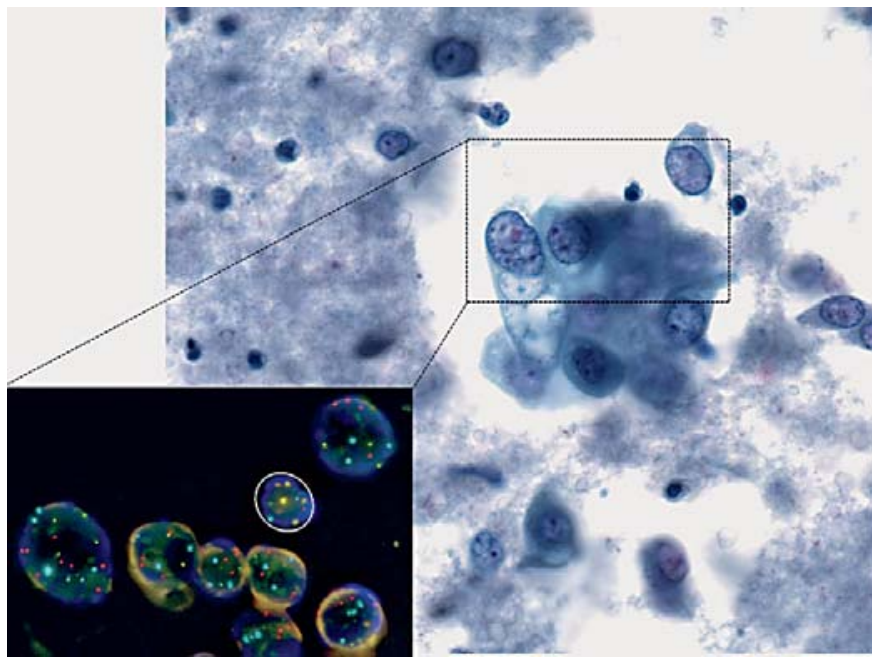

Fig. 8. FISH test (cytospin, original magnification Papanicolaou stain, $600 \times$ ). Bladder washing 3 months after intravesical BCG treatment for pT1, HGUC. Atypical urothelial cells in a background of inflammation support the diagnosis of AUC. Nevertheless, morphology cannot distinguish between neoplastic cells and reactive cellular changes. Insert of the same atypical cell group, UroVysion FISH clearly shows a positive result with gain of the centromeric signals (blue, red, and green) and homozygous deletion of 9p21 (no yellow signals). Encircled is an inflammatory cell, which shows a regular disomic signal pattern and serves as internal negative control (original magnification, 600×).

io, the ancillary test does not add any additional clinical benefit, only unnecessary cost. The UroVysion FISH test can increase the sensitivity of cytology for the detection of LGUC from 25 to 60 to $75 \%$, but usually lowgrade neoplasms are clearly visible by cystoscopy and the FISH result will not impact the clinical management. Conversely, in the setting of atypia with negative or inconclusive findings on cystoscopy, a negative UroVysion FISH test makes it very unlikely that these abnormal cells derive from a HGUC and this additional information will help the urologist in further management of the patient [59].

In general, the ancillary test might be of potential use for clarifying atypia in urinary cytology (fig. 8) and may be able to assist the urologist in clinical management. Nonetheless, testing must be well standardized, performed in the hands of experienced cytomorphologists (if it is a morphology-based assay), under consideration of cystoscopy findings, and the patient's medical history. 
Table 4. Relative risk of the diagnostic categories outlined in The Paris System, based on studies to date.

\begin{tabular}{|c|c|c|}
\hline Category & $\begin{array}{l}\text { Risk of } \\
\text { malignancy, \% }\end{array}$ & Management \\
\hline Unsatisfactory/nondiagnostic & $<5-10$ & $\begin{array}{l}\text { repeat cytology, cystoscopy in } 3 \text { months if increased clinical } \\
\text { suspicion }\end{array}$ \\
\hline Negative for high-grade urothelial carcinoma & $0-10$ & clinical follow-up as needed \\
\hline Atypical urothelial cells & $8-35$ & clinical follow-up as needed; potential use of ancillary testing \\
\hline High-grade urothelial carcinoma & $>90$ & more aggressive follow-up, cystoscopy, biopsy, staging \\
\hline Other malignancy & $>90$ & more aggressive follow-up, cystoscopy, biopsy, staging \\
\hline
\end{tabular}

\section{Conclusions}

Important ongoing work by The Paris System Working Group will provide a standardized platform for reporting cytologic interpretation of urine samples. The relative risk of the diagnostic categories outlined in The Paris System, based on studies to date are outlined in this paper (table 4). Prospective studies to establish successful prediction of HGUC by all categories, and clinical outcomes relative to each morphologic category, will be essential to the successful acceptance and implementation of TPS. For urologists, understanding the diagnostic criteria, their clinical implications, and appreciating the limitations of TPS is necessary if we are to utilize urine cytology and ancillary tests in a thoughtful and practical manner.

\section{Acknowledgements}

The authors would like to thank all who were involved in creating The Paris System of Reporting Urinary Cytology. This was truly a team effort.

\section{Funding Sources}

The authors have not received any grant funding for this paper or for developing The Paris System of Reporting Urinary Cytology.

\section{Disclosure Statement}

The authors do not have any financial conflict of interest to disclose.

\section{References}

1 Blick CG, Nazir SA, Mallett S, et al: Evaluation of diagnostic strategies for bladder cancer using computed tomography (CT) urography, flexible cystoscopy and voided urine cytology: results for 778 patients from a hospital haematuria clinic. BJU Int 2012;110:84-94.

$>2$ Layfield LJ, Elsheikh TM, Fili A, Nayar R, Shidham V; Papanicolaou Society of Cytopathology: Review of the state of the art and recommendations of the Papanicolaou Society of Cytopathology for urinary cytology procedures and reporting : the Papanicolaou Society of Cytopathology Practice Guidelines Task Force. Diagn Cytopathol 2004;30:24-30.

$>3$ Netto GJ: Molecular genetics and genomics progress in urothelial bladder cancer. Semin Diagn Pathol 2013;30:313-320.
4 Cheng L, Zhang S, MacLennan GT, Williamson SR, Lopez-Beltran A, Montironi R: Bladder cancer: translating molecular genetic insights into clinical practice. Hum Pathol 2011; 42:455-481.

5 Knowles MA: Molecular pathogenesis of bladder cancer. Int J Clin Oncol 2008;13:287297.

-6 van Rhijn BW: Combining molecular and pathologic data to prognosticate non-muscleinvasive bladder cancer. Urol Oncol 2012;30. 518-523.

7 Redman R, Yoder BJ, Massoll NA: Perceptions of diagnostic terminology and cytopathologic reporting of fine-needle aspiration biopsies of thyroid nodules: a survey of clinicians and pathologists. Thyroid 2006;16: 1003-1008.
8 Lankshear S, Srigley J, McGowan T, Yurcan M, Sawka C: Standardized synoptic cancer pathology reports - so what and who cares? A population-based satisfaction survey of 970 pathologists, surgeons, and oncologists. Arch Pathol Lab Med 2013;137:1599-1602.

$\checkmark 9$ Powsner SM, Costa J, Homer RJ: Clinicians are from Mars and pathologists are from Venus. Arch Pathol Lab Med 2000;124:10401046.

10 Troxel DB: The pathology report: reducing malpractice risk. 2005. http://www.thedoctors.com/KnowledgeCenter/PatientSafety/ [serial online] (accessed March 10, 2016). 
11 Statistics NCoVaH, Information for health: A Strategy for Building the National Health Information Infrastructure. Report and Recommendations from the National Committee on Vital and Health Statistics. Washington, U.S. Department of Health and Human Services, 2001.

12 Grapsa D, Ekaterini P: Standardized categorical reporting of cytopathology results: the strengths and weaknesses of a constantly evolving and expanding system. Diagn Cytopathol 2013;41:917-921.

13 Ali SZ, Leteurtre E: The official nomenclature and terminologies in diagnostic cytopathology: history, evolution, applicability and future. Ann Pathol 2012;32:e3-e7, 389-393.

14 The 1988 Bethesda System for reporting cervical/vaginal cytological diagnoses. National Cancer Institute Workshop. JAMA 1989;262: 931-934.

15 Davey DD, Austin RM, Birdsong G, et al: ASCCP patient management guidelines: Pap test specimen adequacy and quality indicators. Am J Clin Pathol 2002;118:714-718.

-16 Wright TC Jr, Cox JT, Massad LS, et al: 2001 consensus guidelines for the management of women with cervical intraepithelial neoplasia. Am J Obstet Gynecol 2003;189:295-304.

-17 Stoler MH, Castle PE, Solomon D, Schiffman M: American Society for Colposcopy and Cervical Pathology. The expanded use of HPV testing in gynecologic practice per ASCCP-guided management requires the use of well-validated assays. Am J Clin Pathol 2007;127:335-337.

18 Massad LS, Einstein MH, Huh WK, et al: 2012 updated consensus guidelines for the management of abnormal cervical cancer screening tests and cancer precursors. Obstet Gynecol 2013;121:829-846.

19 Schiffman M, Solomon D: Findings to date from the ASCUS-LSIL Triage Study (ALTS). Arch Pathol Lab Med 2003;127:946-949.

20 Crippa S, Mazzucchelli L, Cibas ES, Ali SZ: The Bethesda System for reporting thyroid fine-needle aspiration specimens. Am J Clin Pathol 2010;134:343-344, author reply 345.

21 Darragh TM, Colgan TJ, Cox JT, et al: The Lower Anogenital Squamous Terminology Standardization Project for HPV-Associated Lesions: background and consensus recommendations from the College of American Pathologists and the American Society for Colposcopy and Cervical Pathology. Arch Pathol Lab Med 2012;136:1266-1297.

22 Crothers BA, Tench WD, Schwartz MR, et al: Guidelines for the reporting of nongynecologic cytopathology specimens. Arch Pathol Lab Med 2009;133:1743-1756.

23 Mazhari R, Kimmel PL: Hematuria: an algorithmic approach to finding the cause. Cleve Clin J Med 2002;69:870, 872-874, 876 passim.

24 Hall MC, Chang SS, Dalbagni G, et al: Guideline for the management of nonmuscle invasive bladder cancer (stages Ta, T1, and Tis): 2007 update. J Urol 2007;178:2314-2330.
25 Babjuk M, Burger M, Zigeuner R, et al: EAU guidelines on nonmuscle-invasive urothelial carcinoma of the bladder: update 2013. Eur Urol 2013;64:639-653.

26 Clark PE, Agarwal N, Biagioli MC, et al: Bladder cancer. J Natl Compr Canc Netw 2013;11: 446-475.

27 van der Aa MN, Steyerberg EW, Bangma C, van Rhijn BW, Zwarthoff EC, van der Kwast TH: Cystoscopy revisited as the gold standard for detecting bladder cancer recurrence: diagnostic review bias in the randomized, prospective CEFUB trial. J Urol 2010;183:76-80

28 Khan R, Hussain H, Pambuccian S, Wojcik E, Barkan G: What is the negative predictive value of urinary tract cytology. J Am Soc Cytopathol 2015;4:S21-S22.

29 Aharony S, Baniel J, Yossepowitch O: Clinically unconfirmed positive urinary cytology: diagnostic implications and oncological outcomes. BJU Int 2011;108:E179-E183.

30 Glatz K, Willi N, Glatz D, et al: An international telecytologic quiz on urinary cytology reveals educational deficits and absence of a commonly used classification system. Am J Clin Pathol 2006;126:294-301

-31 Studeman KD, Ioffe OB, Puszkiewicz J, Sauvegeot J, Henry MR: Effect of cellularity on the sensitivity of detecting squamous lesions in liquid-based cervical cytology. Acta Cytol 2003;47:605-610

32 Solomon D, Nayar R: The Bethesda System for Reporting Cervical Cytology: Definitions, Criteria, and Explanatory Notes, ed 2. New York, Springer, 2004.

33 Goellner JR, Gharib H, Grant CS, Johnson DA: Fine needle aspiration cytology of the thyroid, 1980-1986. Acta Cytol 1987;31:587590.

34 Grant CS, Hay ID, Gough IR, McCarthy PM, Goellner JR: Long-term follow-up of patients with benign thyroid fine-needle aspiration cytologic diagnoses. Surgery 1989;106:980-985, discussion 985-986.

35 Cibas ES, Ali SZ: The Bethesda System For Reporting Thyroid Cytopathology. Am J Clin Pathol 2009;132:658-665.

36 Pitman MB, Centeno BA, Ali SZ, et al: Standardized terminology and nomenclature for pancreatobiliary cytology: the Papanicolaou Society of Cytopathology guidelines. Diagn Cytopathol 2014;42:338-350.

- 37 Alsharif M, Andrade RS, Groth SS, Stelow EB, Pambuccian SE: Endobronchial ultrasoundguided transbronchial fine-needle aspiration: the University of Minnesota experience, with emphasis on usefulness, adequacy assessment, and diagnostic difficulties. Am J Clin Pathol 2008:130:434-443.

38 Nayak A, Sugrue C, Koenig S, Wasserman PG, Hoda S, Morgenstern NJ: Endobronchial ultrasound-guided transbronchial needle aspirate (EBUS-TBNA): a proposal for on-site adequacy criteria. Diagn Cytopathol 2012;40: 128-137.
39 Cameron SE, Andrade RS, Pambuccian SE: Endobronchial ultrasound-guided transbronchial needle aspiration cytology: a state of the art review. Cytopathology 2010;21:626.

40 Prather J, Arville B, Chatt G, et al: Evidencebased adequacy criteria for urinary bladder barbotage cytology. J Am Soc Cytopathol 2015;4:57-62.

41 VandenBussche CJ, Rosenthal DL, Olson MT: Adequacy in voided urine cytology specimens: the role of volume and a repeat void upon predictive values for high-grade urothelial carcinoma. Cancer Cytopathol 2015;124: 174-180.

42 Barkan GA: Enough Is enough: adequacy of voided urine cytology. Cancer Cytopathol 2015;124:163-166.

43 Wojcik EM: What should not be reported as atypia in urine cytology. J Am Soc Cytopathol 2015;4:30-36.

44 Renshaw AA: Subclassifying atypical urinary cytology specimens. Cancer 2000;90:222229 .

45 Brimo F, Vollmer RT, Case B, Aprikian A, Kassouf W, Auger M: Accuracy of urine cytology and the significance of an atypical category. Am J Clin Pathol 2009;132:785-793.

46 Piaton E, Advenier AS, Benaim G, Petrucci MD, Lechevallier FM, Ruffion A: Atypical urothelial cells (AUC): a Bethesda-derived wording applicable to urinary cytopathology (in French). Ann Pathol 2011;31:11-17.

47 Rosenthal DL, Vandenbussche CJ, Burroughs FH, Sathiyamoorthy S, Guan H, Owens C: The Johns Hopkins Hospital template for urologic cytology samples: part I-creating the template. Cancer Cytopathol 2013;121:1520.

48 McCroskey Z, Bahar B, Hu Z, Wojcik EM, Barkan GA: Subclassifying atypia in urine cytology: what are the helpful features? J Am Soc Cytopathol 2015;4:183-189.

49 Koss LG, Melamed MR, Koss LG: Koss' Diagnostic Cytology and its Histopathologic Bases, ed 5. Philadelphia, Lippincott Williams and Wilkins, 2006

50 Papanicolaou GN, Marshall VF: Urine sediment smears as a diagnostic procedure in cancers of the urinary tract. Science 1945;101: 519-520.

-51 Reid MD, Osunkoya AO, Siddiqui MT, Looney SW: Accuracy of grading of urothelial carcinoma on urine cytology: an analysis of interobserver and intraobserver agreement. Int J Clin Exp Pathol 2012;5:882-891

52 Raab SS, Slagel DD, Jensen CS, et al: Lowgrade transitional cell carcinoma of the urinary bladder: application of select cytologic criteria to improve diagnostic accuracy [corrected]. Mod Pathol 1996;9:225-232.

53 Raab SS, Lenel JC, Cohen MB: Low grade transitional cell carcinoma of the bladder. Cytologic diagnosis by key features as identified by logistic regression analysis. Cancer 1994; 74:1621-1626. 
-54 Xin W, Raab SS, Michael CW: Low-grade urothelial carcinoma: reappraisal of the cytologic criteria on ThinPrep. Diagn Cytopathol 2003;29:125-129.

-55 Murphy WM, Soloway MS, Jukkola AF, Crabtree WN, Ford KS: Urinary cytology and bladder cancer. The cellular features of transitional cell neoplasms. Cancer 1984;53: 1555-1565.
56 McCroskey Z, Pambuccian SE, Kleitherms S, et al: Accuracy and interobserver variability of the cytologic diagnosis of low-grade urothelial carcinoma in instrumented urinary tract cytology specimens. Am J Clin Pathol 2015; 144:902-908

57 Sokolova IA, Halling KC, Jenkins RB, et al: The development of a multitarget, multicolor fluorescence in situ hybridization assay for the detection of urothelial carcinoma in urine. J Mol Diagn 2000;2:116-123.
58 Dimashkieh H, Wolff DJ, Smith TM, Houser PM, Nietert PJ, Yang J: Evaluation of urovysion and cytology for bladder cancer detection: a study of 1,835 paired urine samples with clinical and histologic correlation. Cancer $\mathrm{Cy}$ topathol 2013;121:591-597.

59 Tapia C, Glatz K, Obermann EC, et al: Evaluation of chromosomal aberrations in patients with benign conditions and reactive changes in urinary cytology. Cancer Cytopathol 2011; 119:404-410. 